\title{
Anti-tumour necrosis factor $\alpha$ therapy: can we afford it?
}

\section{P M Symmons}

\section{Cost is now a factor in selecting treatment}

$\mathrm{T}$ he introduction of biological agents into the therapeutic armamentarium for rheumatoid arthritis (RA) has ushered in a new era for rheumatologists in more ways than one Randomised controlled trials (RCTs) and longitudinal observational studies provide clear evidence that the use of these agents is associated with a greater proportion of responders and a better response than with conventional disease modifying antirheumatic drugs (DMARDs) such as methotrexate (MTX). ${ }^{1-9}$ However, these drugs are substantially more expensive than conventional DMARDs. This means that, whether we like it or not (and most of us don't like it), cost is now one of the factors we have to consider when selecting treatment for patients with RA. Perhaps for the first time rheumatologists are having to take part in the process of healthcare policy making and endeavour to understand the language of cost effectiveness analysis (CEA). CEA compares the incremental cost of an intervention (in this case antitumour necrosis factor $\alpha(\mathrm{TNF} \alpha)$ therapy) over the cost of conventional treatment with its incremental health benefit. $^{10}$

The paper published in this issue of the Annals by Bansback et al is based on a CEA funded by Abbott Laboratories, the manufacturers of adalimumab, for submission to the Swedish Government. ${ }^{11}$ It is to be welcomed that the work is published in an academic peer reviewed journal because health economic modelling is as much a legitimate scientific endeavour as the RCTs which led to the drug being licensed.

\section{COST EFFECTIVENESS}

The first question posed by healthcare purchasers when a new, but expensive, biological drug is licensed for RA is, "Is this particular biological agent cost effective for the treatment of RA?" or, in other words, "should any patients with RA receive this drug?" This requires consideration of the response and cost of treatment of the "average" patient with RA. In considering this question, the health economist has a number of major handicaps. These analyses are required by policy makers at a time when the data on which they can be based are very limited. The policy makers need to decide whether they will fund a drug when it is new to the market-and the only published data are a few RCTs.

Thus, the paper by Bansback et al is based on 137 patients treated with infliximab, 260 with etanercept, and 387 with adalimumab. These patients will not be typical of those for whom the economic model must be applied because patients with comorbidity are explicitly excluded from RCTs. Although RCTs only extend for 6-12 months, the health economist must model the costs and benefits of the new treatment over many years-or even the lifetime of the patients. This requires a number of assumptions to be made and requires epidemiological data on the natural history of treated RA to be "borrowed" from other sources. It is important that rheumatologists should be involved in the development and interpretation of these models - and that the full models together with their data sources are published. Maetzel reviewed 6 CEAs for infliximab and etanercept. ${ }^{12}$ The cost per quality adjusted life year (QALY) ranged from $\$ 26000^{13}$ to $\$ 180000 .^{14}$ The differences are most likely to be attributable to the model specifications and assumptions made by the authors.

"Policy makers have to decide whether a treatment is cost effective when little information is available"

CEAs are usually presented as cost utility rates because health benefit is then measured in QALYs, and this enables a comparison of costs across diseases and interventions. QALYs also have the advantage of combining the positive and negative (adverse events) outcomes of an intervention. Unfortunately, the majority of rheumatology RCTs do not include a health utility measure (such as the EQ5D (a version of the European Quality of Life (EuroQol)) or Health Utility Index
(HUI)). OMERACT has sought to deal with this deficiency by recommending the parallel collection of disease-specific, generic quality of life, and health utility measures in RCTs. ${ }^{15}$ In the meantime, mapping from existing outcome measures (such as the Health Assessment Questionnaire (HAQ)) to a health utility measure has to be performed using an external data source. In the study by Bansback et al, mapping from the HAQ to the HUI-3 was developed using the adalimumab trials and then applied to the etanercept and infliximab trials. Further work is needed to establish how robust and transferable such maps are.

\section{WHO SHOULD RECEIVE A BIOLOGICAL AGENT?}

The vast differential costs of the biological agents compared with conventional DMARDs challenge the usual way of interpreting RCTs. In the past, RCTs focused on average responses-for example, the mean change in the HAQ score in patients treated with drug A would be compared with the mean change with drug $\mathrm{B}$. The conclusion was that if patients taking drug A did better overall than patients taking drug B then all patients with disease characteristics similar to those in the trial should be treated with drug A. But such a presentation of the results masks the true picture. It is unlikely that every single person in the trial did somewhat better on drug A than they would have done on drug B. More likely is that a higher proportion of patients responded to drug A, but some patients will still have responded to drug $\mathrm{B}$.

This is what we see in the biological trials. There are more American College of Rheumatology (ACR) 20 responders to biological agents than to MTX. Nevertheless, some patients in the MTX arm do very well-especially in early disease. If we could predict which patients would not respond to MTX but would respond to a biological agent then these would be the people for whom the drug would be most cost effective.

The biological agents will also be most cost effective in responders with high baseline disease activity or HAQ scores because these patients have the greatest potential for improvement. The milder the baseline disease, the less room for improvement. Non-responders incur all the cost of treatment but no benefit. The higher the proportion of non-responders in the total pool of treated cases, the lower the cost-utility ratio will be. But RCTs are not powered to explore predictors of response. We need large longitudinal observational studies and better predictors of response. ${ }^{16}$ This approach is needed to answer the 
second question asked by policy makers, "Which patients with RA should receive this biological agent", because clearly they are not going to fund it for all patients. At the moment, national guidelines respond by saying, "those who satisfy the criteria for entry to the published RCTs". But this is sticking with the old paradigm of average response. The answer should be, "those patients with RA most likely to respond or those least likely to develop adverse events, or both."

\section{ECONOMIC MODELS}

Economic models depend on conditional probability. Given that the patient is treated with a biological agent what is the probability of response/adverse event and so on. Hence the need to be able to predict response. The models also ask very reasonable-but often unanswerable questions-about the natural history of treated RA. What is the mean HAQ score of responders to biological agents? What is the effect of biological treatment on hospitalisation rates in the next year or so? As time goes by, some of these questions will be answered from "real" data which is being accumulated by those biological registers with a control, non-biological exposed group. ${ }^{17}$ In the meantime, we need to search our existing datasets to try to provide the information required by the policy makers and work with health economists to develop economic models which reflect the type of patients, response rate, and comparator likely to be encountered in routine clinical practice.

Ann Rheum Dis 2005;64:969-970. doi: 10.1136/ard.2005.037564
Correspondence to: Professor D P M Symmons, ARC Epidemiology Unit, Stopford Building, University of Manchester, Oxford Road, Manchester M13 9PT, UK; deborah.symmons@ man.ac.uk

\section{REFERENCES}

1 Maini R, St Clair EW, Breedveld F, Furst D, Kalden J, Weisman $M$, et al. Infliximab (chimeric anti-tumour necrosis factor alpha monoclonal antibody) versus placebo in rheumatoid arthritis patients receiving concomitant methotrexate: a randomised phase III trial. ATTRACT Study Group. Lancet 1999:354:1932-9.

2 Kavanaugh A, St Clair EW, McCune WJ, Braakman T, Lipsky P. Chimeric anti-tumor necrosis factor-alpha monoclonal antibody treatment of patients with rheumatoid arthritis receiving methotrexate therapy. J Rheumatol 2000;27:841-50.

3 Lipsky PE, van der Heijde DM, St Clair EW, Furst DE, Breedveld FC, Kalden JR, et al. Infliximab and methotrexate in the treatment of rheumatoid arthritis. Anti-Tumor Necrosis Factor Trial in Rheumatoid Arthritis with Concomitant Therapy Study Group. N Engl J Med 2000;343:1594-602.

4 Moreland LW, Schiff MH, Baumgartner SW, Tindall EA, Fleischmann RM, Bulpitt KJ, et al. Etanercept therapy in rheumatoid arthritis. A randomized, controlled trial. Ann Intern Med 1999;130:478-86.

5 Weinblatt ME, Kremer JM, Bankhurst AD, Bulpitt KJ, Fleischmann RM, Fox RI, et al. A trial of etanercept, a recombinant tumor necrosis factor receptor:Fc fusion protein, in patients with rheumatoid arthritis receiving methotrexate. N Engl J Med 1999;340:253-9.

6 Klareskog L, van der Heiide D, de Jager JP, Gough A, Kalden J, Malaise M, et al. Therapeutic effect of the combination of etanercept and methotrexate compared with each treatment alone in patients with rheumatoid arthritis: double-blind randomised controlled trial. Lancet 2004;363:675-81

7 Weinblatt ME, Keystone EC, Furst DE, Moreland LW, Weisman MH, Birbara CA, et al. Adalimumab, a fully human anti-tumor necrosis factor alpha monoclonal antibody, for the treatment of rheumatoid arthritis in patients taking concomitant methotrexate: the ARMADA trial. Arthritis Rheum 2003:48:35-45.

8 Keystone EC, Kavanaugh AF, Sharp JT, Tannenbaum H, Hua Y, Teoh LS, et al.
Radiographic, clinical, and functional outcomes of treatment with adalimumab (a human anti-tumor necrosis factor monoclonal antibody) in patients with active rheumatoid arthritis receiving concomitant methotrexate therapy: a randomized, placebo-controlled, 52-week trial. Arthritis Rheum 2004;50:1400-11

9 van de Putte LB, Atkins C, Malaise M, Sany J, Russell AS, van Riel PL, et al. Efficacy and safety of adalimumab as monotherapy in patients with rheumatoid arthritis for whom previous disease modifying antirheumatic drug treatment has failed. Ann Rheum Dis 2004:63:508-16.

10 Cartwright WS. Methods for the economic evaluation of health care programmes, second edition. By Michael F. Drummond, Bernie O'Brien, Greg L. Stoddart, George W. Torrance. Oxford: Oxford University Press, 1997, J Ment Health Policy Econ 1999;2:43.

11 Bansback NJ, Brennan A, Ghatnekar O. Cost effectiveness of adalimumab in the treatment of patients with moderate to severe rheumatoid arthritis in Sweden. Ann Rheum Dis 2005;64:995-1002.

12 Maetzel A. Cost-effectiveness estimates reported for tumor necrosis factor blocking agents in rheumatoid arthritis refractory to methotrexatea brief summary. J Rheumatol Suppl 2005;72:51-3.

13 Brennan A, Bansback N, Reynolds A, Conway P. Modelling the cost-effectiveness of etanercept in adults with rheumatoid arthritis in the UK. Rheumatology (Oxford) 2004;43:62-72

14 Jobanputra $P$, Barton $P$, Bryan S, Burls A. The effectiveness of infliximab and etanercept for the treatment of rheumatoid arthritis: a systematic review and economic evaluation. Health Technol Assess 2002;6:1-110.

15 Maetzel A, Tugwell P, Boers M, Guillemin F, Coyle D, Drummond $M$, et al. Economic evaluation of programs or interventions in the management of rheumatoid arthritis: defining a consensus-based reference case. J Rheumatol 2003:30:891-6

16 Hider SL, Buckley C, Silman AJ, Symmons DP, Bruce IN. Factors influencing response to disease modifying antirheumatic drugs in patients with rheumatoid arthritis. J Rheumatol 2005:32:11-16.

17 Kobelt G, Eberhardt K, Geborek P. TNF inhibitors in the treatment of rheumatoid arthritis in clinical practice: costs and outcomes in a follow up study of patients with RA treated with etanercept or infliximab in southern Sweden. Ann Rheum Dis 2004;63:4-10. 